\title{
SISTEM INFORMASI MANAJEMEN PERSEDIAAN SUKU CADANG PADA PERUSAHAAN PENYEWAAN KENDARAAN
}

\author{
Yuana Delvika \\ Dosen Program Studi Teknik Industri, Fakultas Teknik, Universitas Medan Area \\ Jl. Kolam No. 1 Medan \\ yuana_delvika@yahoo.com
}

\begin{abstract}
Abstrak. Persediaan suku cadang tepat waktu merupakan aset yang cukup penting pada perusahaan penyewaan kendaraan khususnya dalam penyelesaian program perawatan dan perbaikan tepat waktu sehingga kendaraan yang siap pakai tersedia pada saat dibutuhkan. Kenyataannya di perusahaan, pada bulan Februari, ada 104 jam waktu menganggur karena menunggu suku cadang tiba di lokasi perbaikan. Pada bulan Maret, ada 169 jam waktu menganggur akibat suku cadang terlambat tiba. Dan pada bulan April, ada 161 jam waktu menganggur untuk menunggu suku cadang tiba. Hal ini menyebabkan seringnya terjadi keterlambatan dalam pengadaan suku cadang sehubungan dengan ketidakjelasan sistem informasi dalam pengelolaan suku cadang. Untuk mengatasi permasalahan di atas, maka dilakukan perancangan data base dan perancangan sistem informasi. Perancangan data base dengan melakukan pengkodean grup suku cadang, pengkodean suku cadang, pengklasifikasian suku cadang dan penentuan elemen-elemen persediaan. Perancangan sistem informasi yang dilakukan dengan metode unified modelling language. Hasil yang diperoleh dengan menerapkan sistem ini adalah pengematan Rp. 9,090,432.56 untuk suku cadang jenis ban, penghematan Rp. 947,025.47 untuk suku cadang jenis ban dalam, penghematan Rp. 1,298,446.09 untuk suku cadang jenis oli, penghematan Rp. 1,198,187.93 untuk suku cadang jenis oli hidrolik, penghematan Rp. 1,559,882.97 untuk suku cadang jenis minyak pelumas, penghematan Rp. 1,285,816.22 untuk suku cadang jenis ban vulkanisir dan penghematan Rp. 5,843,724.47 untuk suku cadang jenis selendang ban.
\end{abstract}

Kata Kunci. persediaan, pengendalian suku cadang, sistem informasi

Abstract. The availability of spare parts in time is an important asset in a heavy equipment retailing company especially in the completion of maintaining and repairing program as per the schedule. So that the heavy equipment will be available when needed. In fact, there were 107 idle hours in february, 169 idle hours in March and 161 idle hours on April caused by the absence of various spare parts needed in restoration site. All these factors caused the referdation of spare parts supply in accordance to imprecision of information system in spare parts handling and procurement. Designing of database and information system is made, in order to over come the above matters. Database designing by spare part clasifications, clarifications and stipulations of stock elements. And the design of informations system by "unified modeling language" method. The result of implementing this system is obstemiousness of Rp. 9,090,432.56 for Tire, Rp. 947,025.47 for Tube, Rp. 1,298,446.09 for Engine oil, Rp. 1,198,187.93 for Hydraulic oil, Rp. 1,559,882.97 for Bearing, Rp. 1,285,816.22 for Tire vulcanizer and Rp. 5,843,724.47 for Rim.

\section{Keywords. Inventory, Spare Parts Controlling, Information System}




\section{Pendahuluan}

Persediaan suku cadang merupakan aset yang cukup penting pada perusahaan penyewaan alat berat. Menurut Assauri (1998) persediaan terhadap suku cadang sangat perlu karena jika jumlah persediaan lebih kecil dari jumlah suku cadang yang rusak, maka akan menyebabkan alat berat tidak dapat beroperasi. Hal ini akan menimbulkan kerugian yang sangat besar. Demikian pula sebaliknya, jika jumlah persediaan suku cadang di gudang terlalu besar maka akan menimbulkan kerugian seperti tertanamnya modal perusahaan.

Suku cadang dari masing-masing alat berat mempunyai waktu kerusakan yang berbeda-beda. Untuk mengurangi kerusakan alat berat sangat diperlukan perencanaan perawatan yang baik. Untuk mendukung rencana perawatan dan perbaikan terhadap alat berat maka dibutuhkan suku cadang. Suku cadang yang tidak tersedia pada saat yang dibutuhkan akan menghambat rencana perawatan dan perbaikan tersebut. Untuk itu pengendalian persediaan suku cadang dalam perusahaan penyewaan alat berat sangat diperlukan untuk menjaga keandalan alat berat dan ketepatan pelaksanaan program perawatan dan perbaikan.

Kenyataan bahwa perusahaan saat ini sudah memiliki sistem informasi pengendalian persediaan suku cadang. Menurut Kenneth C Laudon (2005) sistem informasi tidak bisa sukses tanpa memahami organisasi. Salah satu bentuk pemahaman terhadap organisasi adalah dengan memetakan bisnis proses dan diagram jaringan informasi perusahaan yang digambarkan pada Gambar 1.1 (a) dan Gambar 1.1 (b). Menurut Kenneth C Laudon (2005) Bisnis proses merupakan suatu cara unik dalam mengorganisasikan aktivitas kerja, informasi dan pengetahuan untuk menghasilkan suatu produk atau jasa.

Menurut Henmaidi dalam Jurnal Ilmiah Teknik Industri, Perusahaan melakukan pembagian suku cadang dalam 3 kategori yaitu kategori fast moving, kategori middle moving dan kategori slow moving. Menurut Richardus Eko Indrajit dalam buku Manajemen Persediaan (2003), barang suku cadang dibagi berdasarkan penggunaannya. Pembagian ini sangat berguna untuk membagi kebijakan penyimpanan dan pengisian kembali. Menurutnya juga sebaiknya pembagian dikaitkan dengan tingkat kerusakan alat yang digunakan. Perusahaan juga sudah memiliki sistem pemesanan berdasarkan stok minimum-maksimum. Perusahaan memiliki beberapa prosedur yang mengatur pengendalian persediaan suku cadang.

Menurut Kenneth C Laudon (2005) Prosedur merupakan aturan-aturan formal untuk menyelesaikan tugas yang dikembangkan dengan tujuan mengatasi situasi yang telah diantisipasi sebelumnya.

Kelemahan dari sistem ini adalah suku cadang sering terlambat tiba diperusahaan sehingga program perawatan dan perbaikan sering terlambat.

Sebagai contoh pada bulan Februari, ada 104 jam waktu menganggur karena menunggu spart part tiba di lokasi perbaikan. Pada bulan Maret, ada 169 jam waktu menganggur akibat suku cadang terlambat tiba. Pada bulan April, ada 161 jam waktu menganggur untuk menunggu suku cadang tiba. Kumulatif waktu menunggu ini cukup besar yang mengakibatkan alat berat tidak tersedia pada saat yang dibutuhkan.

Menurut Hermawan, Arya Tandy dalam Seminar Nasional Aplikasi Teknologi Informasi (SNATI 2009) Masalah lain yang sering juga terjadi adalah kesalahan pemesanan suku cadang antara pihak pemesan dan suplier. Selama ini, masalah di atas ada beberapa kali terjadi. Akibatnya alat berat yang siap pakai tidak bisa dikirim sesuai permintaan pengguna di lapangan. Pengguna di lapangan merasa tidak puat yang ditunjukkan melalui complain/klaim yang sering mereka sampaikan.

Kenyataan lain di dalam perusahaan adalah karakteristik suku cadang yang berjumlah amat banyak yaitu kurang lebih 1100 jenis, jika tidak diklasifikasikan dalam bank data secara sistematis sesuai dengan sifat item baik tingkat penyerapan, tingkat kepentingan dan lain sebagainya akan menjadi kendala tersendiri dalam sistem persediaan maupun penyajian informasi. Penyajian informasi yang dimaksud adalah informasi mengenai suku cadang apa yang sudah mencapai batas stok minimum dan harus dipesan kembali sampai dengan informasi suplier suku cadang yang akan dipesan.

Kemudahan memperoleh informasi amat penting dalam mempersiapkan kegiatan operasional maupun kegiatan rutin bagi pihak manajemen. Kemudahan memperoleh informasi menurut pengamatan yang ada saat ini khususnya dalam sistem pengendalian persediaan perlu ditingkatkan agar dapat menunjang penyajian informasi dalam waktu yang cepat dan tepat sesuai dengan kebutuhan pengambil keputusan. Penyajian informasi dalam waktu yang cepat dan tepat tersebut dapat menghilangkan waktu untuk kegiatan yang tidak efektif. Sehingga dapat meningkatkan efektivitas dan produktivitas kerja karyawan pada bagian terkait.

\section{Perumusan Masalah}

Berdasarkan latar belakang seperti diuraikan di atas, permasalahan yang akan dicari pemecahannya melalui penelitian ini adalah seringnya terjadi keterlambatan dalam pengadaan suku cadang sehubungan dengan ketidakjelasan sistem informasi daam pengelolaan suku cadang.

\subsection{Tujuan dan Sasaran Penelitian}

Tujuan penelitian ini adalah untuk mendapatkan rancangan sistem informasi persediaan suku cadang yang efektif dan efisien sehingga rencana pengadaan dan pengendalian suku cadang dapat akurat dalam menunjang program perawatan dan perbaikan.

Sasaran penelitian ini adalah untuk mengembangkan data base, mendata dan menetapkan informasi antar unit terkait dalam sistem informasi, 
merancang formulir yang akan diimplementasikan pada sistem informasi dan mengembangkan sistem pengkodean.

\subsection{Manfaat Penelitian}

Dalam melakukan penelitian ini, ada beberapa manfaat yang bisa diperoleh, antara lain:

1. Sebagai bahan pertimbangan dan masukan serta sebagai bahan informasi dan rekomendasi untuk selanjutnya menjadi referensi bagi perusahaan dalam mengambil keputusan yang berkaitan dengan informasi pengendalian persediaan

2. Sebagai bahan kajian penelitian selanjutnya dan memberikan sumbangan pemikiran khususnya masalah sistem informasi pengendalian persediaan

\section{Metode Penelitian}

Metode penelitian yang digunakan adalah dengan pendekatan action research, yaitu suatu metode yang menyelesaikan suatu indikasi keadaan, gejala pada kondisi yang sudah ada dan sedang berjalan, yang dilakukan dengan pengumpulan data, mentabulasi dan mengklarifikasi serta menginterpretasikan sehingga diperoleh gambaran yang jelas mengenai masalah yang dihadapi dan pada akhirnya usulan pengembangan yang dilakukan.

\subsection{Metode Pengumpulan Data}

Data yang diperlukan dalam penelitian ini dikumpulkan dengan berbagai cara, sebagai berikut:

1. Melakukan observasi langsung, yaitu mencatat sendiri data yang diperlukan yang diperoleh terhadap pengamatan di lapangan.

2. Melakukan Tanya jawab secara langsung dengan pihak yang terkait dalam pengendalian persediaan suku cadang yaitu Divisi Business Support.

3. Melakukan penelusuran berbagai dokumen yang terkait seperti data masa lalu, kebijakan dan berbagai dokumen yang terkait dengan pengendalian persediaan suku cadang.

\subsection{Sumber Data}

Data yang diperlukan dalam penelitian ini secara garis besar terdiri dari dua jenis data, yaitu:

1. Data Primer

Data Primer meliputi Alur informasi pengendalian persediaan yang ada sekarang dan lain-lain.

2. Data Sekunder

Jumlah dan jenis suku cadang, harga beli masingmasing suku cadang, waktu pemesanan untuk masing-masing suku cadang, jumlah permintaan masing-masing suku cadang, jenis kerusakan, ketepatan rencana jadwal dan realisasi program perawatan, kegagalan perbaikan, bisnis proses, kelengkapan sarana dan prasarana yang meliputi material, mekanik, mesin, sistem dan prosedur perbaikan dan lain-lain.

Metodologi ini merupakan sesuatu yang sangat penting karena berhasil tidaknya, demikian juga tinggi rendahnya kualitas hasil penelitiannya sangat ditentukan oleh ketetapan penulis dalam memilih metodologi penelitiannya.

Diagram alir atau tahapan-tahapan dalam melakukan dapat ditunjukkan pada Gambar 1 di bawah ini :

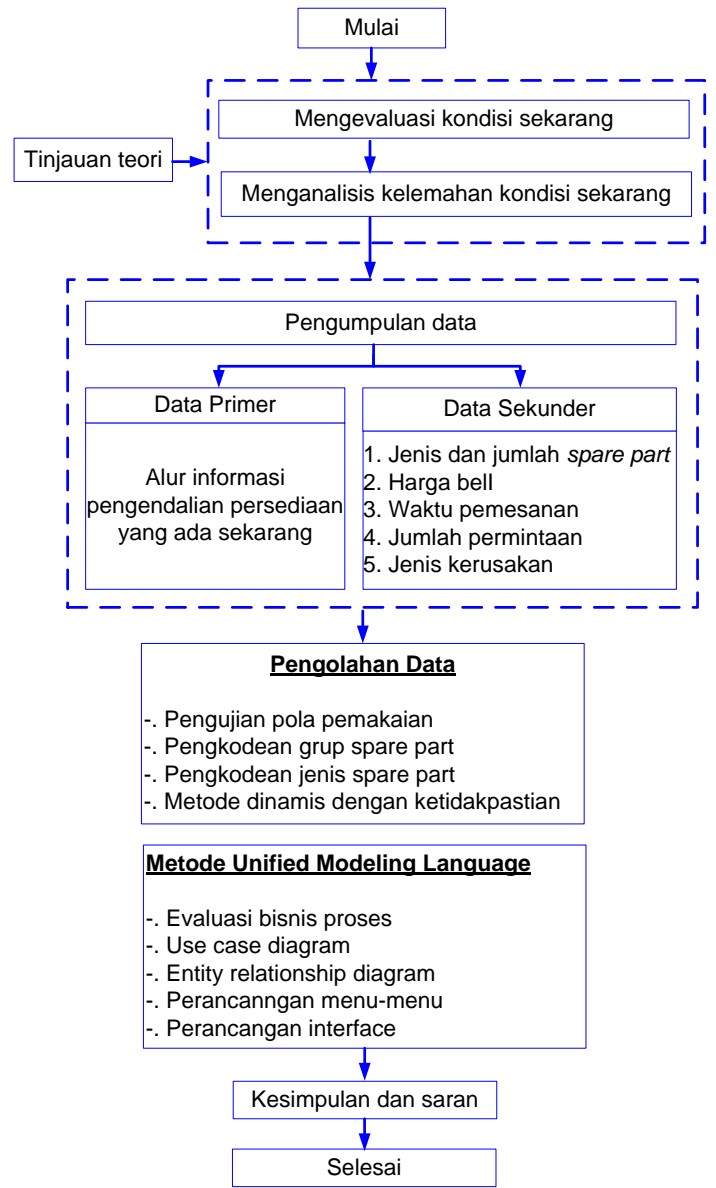

Gambar 1 : Diagram Alir Penelitian

\section{Hasil Penelitian}

Ada 2 (dua) hal yang akan dilakukan dalam perancangan sistem informasi pengendalian persediaan suku cadang yaitu:

1. Perancangan Data Base

Data base yang dimaksud adalah data yang akan menjadi input pada sistem yang akan dibangun. Input adalah kode suku cadang, jumlah pemesanan minimum suku cadang, waktu pemesanan / lead time, jumlah pemesanan minimum masing-masing suku cadang dan total biaya yang dikeluarkan untuk masing-masing suku cadang. Dalam penelitian ini, perancangan data base yang dibuat hanya untuk suku cadang golongan kritis (A).

2. Perancangan sistem informasi

Setelah perancangan data base selesai dilakukan, maka selanjutnya dilakukan perancangan sistem informasi. Sistem informasi yang dirancang melalui proses disain, analisis dan perancangan.

Dalam perancangan sistem informasi ini, semua data yang terkumpul telah dianalisa hubungan antara masing-masing pernyataan dan data yang terkait. Untuk merancang sistem informasi pengendalian persediaan dilakukan pendekatan Unified Modeling Language (UML). Tahapan dalam 
merancang sistem informasi dengan pendekatan UML adalah sebagai berikut:

1. Perencanaan (Planning)

2. Analisis (Analysis)

3. Perancangan (Design)

\section{1) Tahap Perencanaan (Planning)}

Dalam tahapan perencanaan ini ada beberapa kegiatan yang dilakukan yaitu perumusan tujuan pengembangan sistem informasi, survei awal terhadap permasalahan sistem informasi yang ada, analisis sistem dan prosedur yang ada saat ini dan membuat keputusan akhir tentang kelayakan sistem baru.

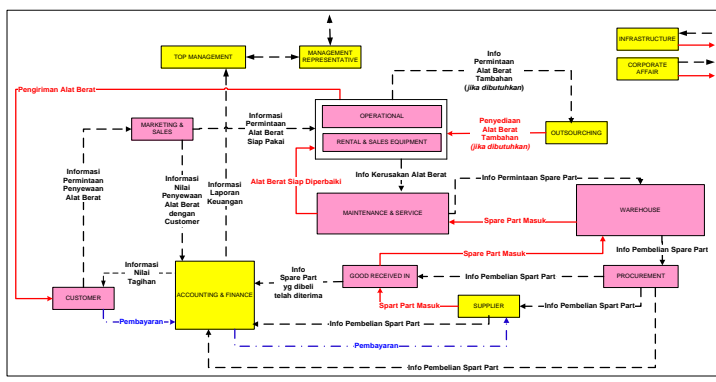

Gambar 2 : Proses Bisnis Usulan

\section{2) Tahap Analisis (Analysis)}

Dalam tahapan analisis ini ada beberapa kegiatan yang akan dilakukan yaitu Mendefinisikan struktur keputusan pada organisasi pengguna, Definisikan pemasalahan dan kebutuhan pada pengguna, Menentukan ruang lingkup sistem yang akan didisain, Mengumpulkan fakta-fakta yang dibutuhkan untuk disain, Mengumpulkan data yang akan dihandel sistem informasi dan Analisis fakta.

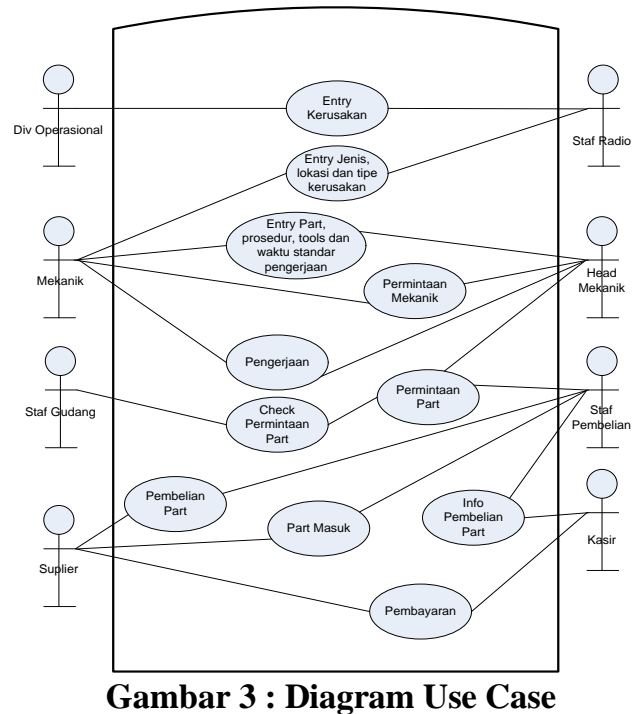

\section{3) Tahap Perancangan (Design)}

Dalam tahapan analisis ini ada beberapa kegiatan yang akan dilakukan yaitu menentukan tujuan umum dan tujuan spesifik sistem informasi, membuat model konseptual, menentukan batasan-batasan sistem, merumuskan operasi dasar pemrosesan data dan pengembangan alternatif disain. Tahapan analisis dapat diinterpretasikan dengan Perancangan Entity
Relationship Diagram (ERD), Perancangan Menu dan Perancangan Antar Muka (Interface).

a) Perancangan Entity Relationship Diagram (ERD) Entity Relationship Diagram (ERD) merupakan suatu model untuk menjelaskan hubungan antar data dalam basis data berdasarkan objek-objek dasar data yang mempunyai hubungan antar relasi. Entity Relationship Diagram (ERD) untuk memodelkan struktur data dan hubungan antar data, untuk menggambarkannya digunakan beberapa notasi dan simbol. Entity Relationship Diagram pengendalian persediaan suku cadang dapat dilihat pada Gambar 4.

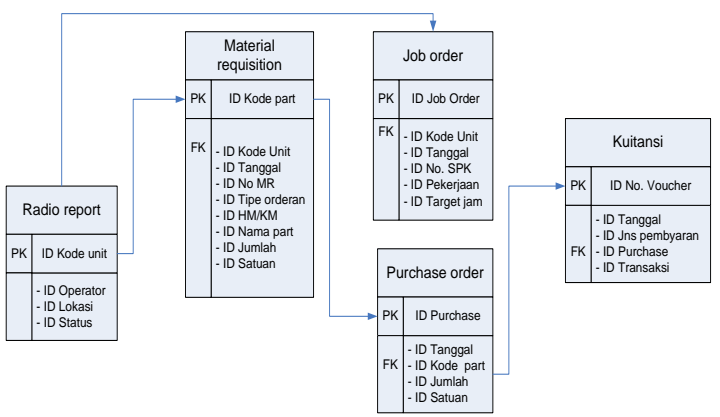

Gambar 4 : Entity Relation Diagram

\section{b) Perancangan Menu}

Perancangan menu dilakukan untuk merancang menu-menu apa yang dibutuhkan dalam kegiatan pengendalian persediaan ini. Menu-menu akan dirancang detail dan akurat agar sistem yang dibangun dapat dijalankan. Adapun rancangan menu pada pengendalian persediaan suku cadang di PT. XYZ dapat ditunjukkan pada Gambar 5.

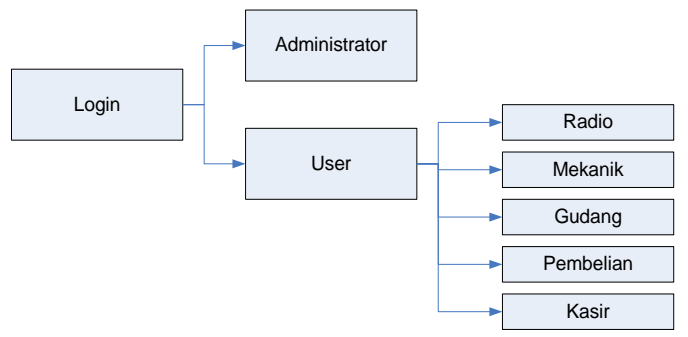

Gambar 5 : Perancangan Menu

\section{c) Perancangan Antar Muka (Interface)}

Setelah mendapatkan field-field maupun informasi apa saja yang mau ditampilkan maka dibuatlah rancangan antarmuka dan untuk memudahkan penjelasan disain antar muka sistem ini. Untuk rancangan antarmuka dapat kita lihat beberapa menu. Rancangan antarmuka yang dibuat interface adalah menu login, menu radio report, menu material requisition, menu job order, menu purchase order dan menu kuitansi seperti yang ditunjukkan pada Gambar 6 . 


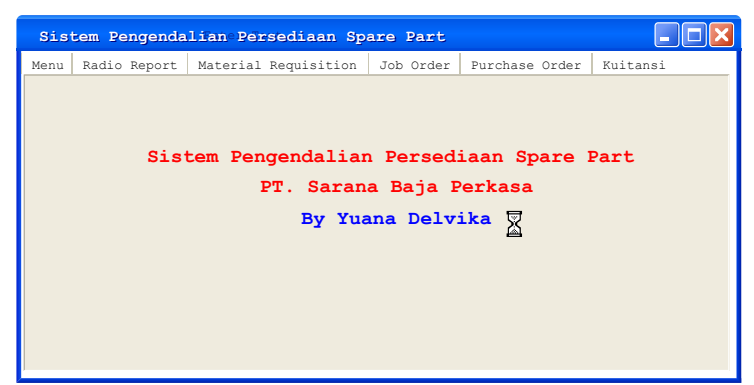

Gambar 6 : Interface

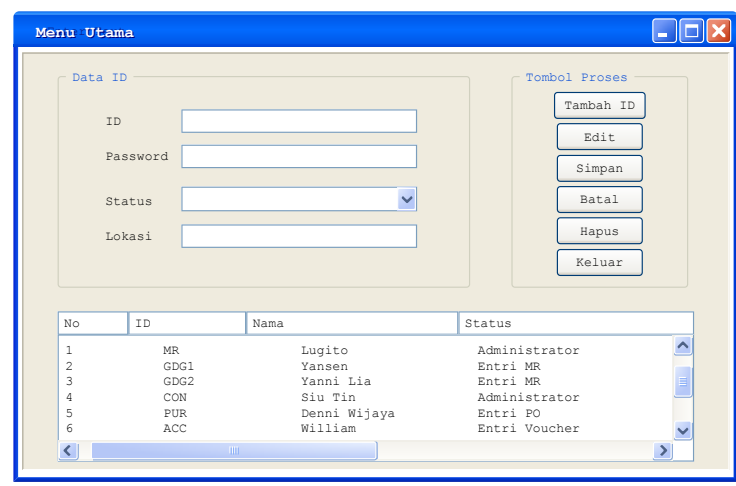

Gambar 7 : Form Login

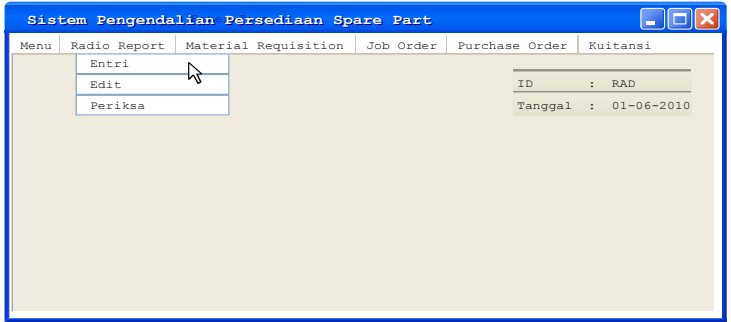

Gambar 8 : Form Radio Report

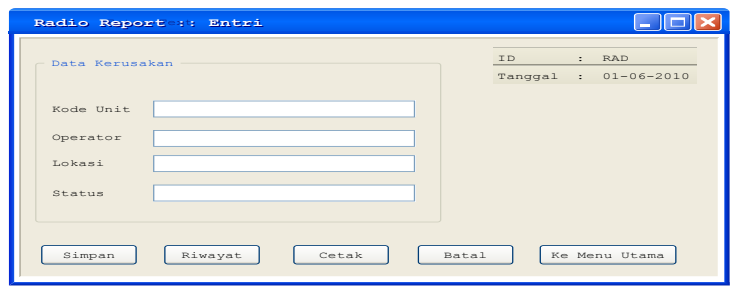

Gambar 9 : Form Entri Radio Report

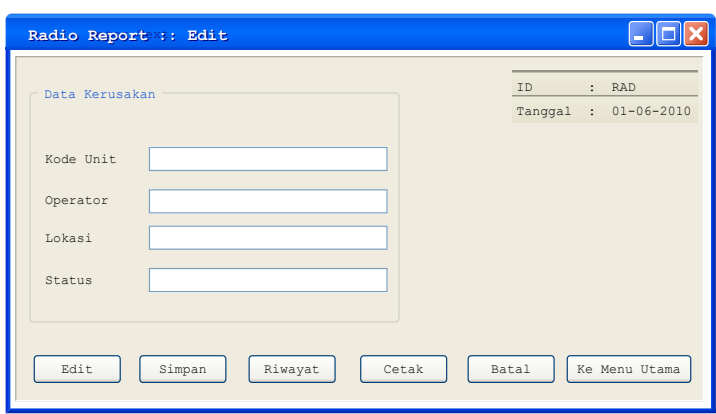

Gambar 10 : Form Edit Radio Report

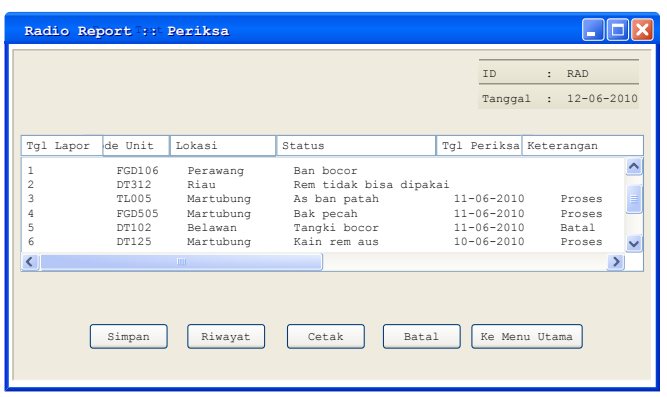

Form 11: Form Periksa Radio Report

\section{Kesimpulan}

1. Berdasarkan klasifikasi suku cadang yang dilakukan maka ada 7 jenis suku cadang kategori kritis (Fast Moving), 26 jenis suku cadang kategori sedang (Middle Moving) dan 833 jenis suku cadang kategori tidak kritis (Slow Moving).

2. Dengan menggunakan klasifikasi $\mathrm{ABC}$ maka yang termasuk suku cadang kategori kritis (Fast Moving) adalah jenis ban, ban dalam, oli mesin, oli hidrolik, bearing, ban vulkanisir, dan selendang ban

3. Model persediaan untuk seluruh suku cadang kategori kritis adalah model dinamis dengan ketidakpastian.

4. Persediaan keamanan untuk jenis ban adalah 7.052 unit, waktu pemesanan 12.692 hari, pemesanan optimal 6.346 unit, pemesanan kembali 13.398 unit dan total biaya persediaan adalah Rp. 246,696,441.10.

5. Persediaan keamanan untuk jenis ban dalam adalah 16.693 unit, waktu pemesanan 22.839 hari, pemesanan optimal 44.251 unit, pemesanan kembali 60.944 unit dan total biaya persediaan adalah Rp. 25,389,392.53.

6. Persediaan keamanan untuk oli mesin adalah 40.767 unit, waktu pemesanan 103.398 hari, pemesanan optimal $1,208.468$ unit, pemesanan kembali 1,249.235 unit dan total biaya persediaan adalah Rp. 7,457,652.36.

7. Persediaan keamanan untuk oli hidrolik adalah 247.340 unit, waktu pemesanan 12.311 hari, pemesanan optimal 677.847 unit, pemesanan kembali 925.187 unit dan total biaya persediaan adalah Rp. 6,927,910.17.

8. Persediaan keamanan untuk bearing adalah 0.240 unit, waktu pemesanan 9.903 hari, pemesanan optimal 0.619 unit, pemesanan kembali 0.859 unit dan total biaya persediaan adalah Rp. 13,316,890.93.

9. Persediaan keamanan untuk ban vulkanisir adalah 9.899 unit, waktu pemesanan 17.317 hari, pemesanan optimal 19.482 unit, pemesanan kembali 29.381 unit dan total biaya persediaan adalah Rp. 9,473,148.12.

10. Persediaan keamanan untuk selendang ban adalah 25.479 unit, waktu pemesanan 4.393 hari, pemesanan optimal 4.668 unit, pemesanan kembali 30.146 unit dan total biaya persediaan adalah Rp. 18,141,369.30.

11. Langkah - langkah perancangan sistem informasi menggunakan bahasa UML (unified modelling 
language) adalah tahap perencanaan (planning) dengan proses bisnis, tahap analisis (analysis) dengan diagram use case, tahap perancangan (design) dengan perancangan entity relationship diagram (ERD), perancangan menu dan perancangan antarmuka (interface).

\section{DAFTAR PUSTAKA}

Albin, S. T. (2003). The art of software architecture : Design, Methods \& Techniques. John Wiley \& Sons.

Anshori Tavip, Aplikasi Sistem Pakar dalam mendukung sistem manajemen informasi, Proceedings, Komputer dan Sistem Inteligen (KOMMIT, 2002), 21-22 Agustus 2002.

Anwaruddin Tanwari, A. Q. (2000). ABC Analysis as a inventory control technique. QUAID $E$ AWAM University Research Journal of Engineering, Science and Technology .

Ballou, R. H. (1999). Business Logistics Management. Prentice Hall International Inc.

Henmaidi, Analisis Kinerja Manajemen Persediaan pada PT.XYZ, Jurnal Ilmiah Teknik Industri

Hermawan, Arya Tandi, Decision Support System Tool untuk penyelesaian masalah, Jurnal
Nasional Aplikasi Teknologi Informasi (SNATI 2009), ISSN : 1907-5022

Hidayati, H. d. (2006). Analisis Kinerja Manajemen Persediaan pada PT.United Tractors Tbk Cabag Padang. Universitas Andalas .

Jauhari, W. A. (2007). Penetapan Tingkat Persediaan Spare Part Forklift Merek Komatsu dengan pendekatan model persediaan single item (studi kasus di PT.United Tractors Tbk). Universitas Sebelas Maret .

Laudon, K. C. (2005). Sistem Informasi Manajemen. Jakarta: Penerbit Andi.

Stallings, W. (2003). Computer Organization \& Architecture. Prentice Hall.

Ultsch, A. (2001). Proof of pareto's 80/20 law and precise limit for $\mathrm{ABC}$ analysis. University of marburg Germany .

Widia, D. (2011). Analisis dan Perancangan Sistem Informasi Manajemen Persediaan untuk Meningkatkan Pengendalian Persediaan Suku Cadang Pesawat pada Divisi Logistik Perusahaan Penerbangan Studi Kasus PT. PAS. Universitas Bina Nusantara . 